\title{
Initial experience with 10 cases of Indiana pouch continent urinary diversion
}

\author{
S.M. Mahbub Alam ${ }^{1}$, Md. Muzharul Hoq ${ }^{1}$, Monwarul Hoque ${ }^{2}$ and Mizanur Rahman² \\ ${ }^{1}$ Department of Urology, Dhaka Medical College, Dhaka 1000; ${ }^{2}$ Department of Urology, \\ Chittagong Medical College. Chittagong, Bangladesh.
}

\begin{abstract}
Indiana pouch continent urinary diversion provides patient control over elimination of urine with periods of dryness. This allows emptying of urine from the pouch by catheter at convenient intervals avoiding major metabolic abnormalities with satisfactory renal function. Detubularization of the ascending colon and caecum with tapering of the terminal ileum and tunneled tenial implants of the ureters have resulted continent cutaneous urinary reservoir. In total 10 patients were included and follow-up period was for a period of 6 months to 5 years. One year after surgery overall day and night continence rate was in $70 \%$ patients, some leakage at day and night in $30 \%$ cases and no patient developed day or night incontinence. The mean capacity of the pouch was $530 \mathrm{ml}$ at 12-18 months. Pouch pressure at full capacity was $16 \mathrm{~cm} \mathrm{H}_{2} \mathrm{O}$ at 18 months. Indiana pouch provides better attention for urinary diversion in developing countries as it is well accepted, economically more suitable and relatively easy to construct, with good results in terms of continence and reduced complications with satisfactory renal function.
\end{abstract}

\section{Introduction}

The goal of any form of urinary diversion is to deliver the urine to outside with a minimum interference of life style, with a maximum protection of the urinary tract.

Orthotopic continent urinary diversion designed from detubularized ileum has gained wide spread acceptance among urologists and the patients and is regarded as the gold standard treatment. But this needs proper patient selection and patient may develop impotence and incontinence. Moreover urethra should be normal in orthotopic neobladder. In ileal conduit the stomal appliance may cause some social and psychological bearings for the patient. Considering the above factors Indiana pouch continent diversion was selected for patients in the present study. Bricker's (1950) ileal conduit has been the most popular diversion which involves management of the stoma and stomal application and is not without long term complications ${ }^{1}$. During the past two decades a changed approach towards continent urinary diversion has emerged which is undoubtedly better accepted by patients ${ }^{2,3 \text {, }}$ 4. In 1950 Gilchrist and associates described the first modern attempt at a continent reservoir constructed with an ileocaecal segment ${ }^{5}$.

In 1987 Rowland et al. modified the Gilchrist procedure to create Indiana pouch a practical continent urinary reservoir ${ }^{4}$.

In Indiana pouch the continence mechanism is provided by ileocaecal valve with reinforcement by Lembert suture. The abdominal stoma remains dry and the reservoir is emptied by clean intermittent self-catheterization (CISC). Detubularized ascending colon and caecum with a portion of terminal ileum is used for construction of this diversion ${ }^{6,7}$.

The purpose of the present study is to provide patient control over elimination of urine with periods of dryness that allows empting of urine from the pouch by catheter at convenient intervals avoiding major metabolic abnormalities with satisfactory renal function. 


\section{Material and Methods}

Between April 2002 and March 2005 we constructed Indiana pouch in 10 patients of which 7 were males and 3 females. Age ranges from 20-64 years (mean $40 \pm 5$ years). The operations were done at the Urology unit of Chittagong Medical College Hospital and a clinic in Chittagong.

Our mean follow-up period was 18 months, range 6 months to 5 years. The indications for operation were muscle invasive carcinoma of urinary bladder in 5, failed VVF repair for several times with loss of urethra and trigon in 3 cases, exstrophy with epispadias in 2 cases.

Pre-operative evaluation: All patients underwent a thorough clinical evaluation, including serum creatinine, blood urea nitrogen and electrolytes before surgery. An upper tract functional evaluation consisting of intravenous urography (IVU) and DTPA renogram were done in all patients, which revealed normal upper tract.

Pre-operative CT scan was done in 5 cases to see the extent of transitional cell carcinoma (TCC) of the urinary bladder. In 6 patients pre-operative colonoscopy was done. Inflammatory stricture was found in one case in the right half of the transverse colon which was excised during operation. Preoperative thorough counseling and method of self catheterization were discussed with the patient. Proper bowel preparation was done before operation.

Total cystectomy with sampling of external iliac and obturator lymph nodes were done in 5 cases with muscle invasive TCC. Neoadjuvant radiochemotherapy was not given in any patient. The VVF patients opted for any sort of urinary diversion as repair failed for 3 times in each cases.

Patients with exstrophy and epispadias presented to us in their adult life and our treatment of choice was urinary diversion. The patients with TCC of urinary bladder were given adjuvant chemotherapy as the lymph nodes were positive for malignancy.

The patients were followed in the immediate postoperative period and at regular intervals. Urinary continence, renal function and status of upper tract were evaluated. Simple cystometry was done in 7 cases, 6-12 months after operation. The term simple cystometry is usually taken to mean the measurement of detrusor pressure during controlled bladder filling, subsequent assessment of detrusor activity, sensation, capacity and compliance.

Surgical techniques: Entire right colon and 8 to 10 $\mathrm{cm}$ segment of terminal ileum were isolated keeping vascularity intact. Ileo-transverse anastomosis was done. The colonic segment was detubularized sparing $2 \mathrm{~cm}$ of the caecal cap. Both the ureters were implanted in the ascending colon in the taenia coli using a tunneled antirefluxing technique. The reservoir was closed transversely using a single layer running 3/0 vicryl. A 22 Fr. Foley catheter was placed through the cap of the caecum to act as a drainage port of the urine for the first three weeks post-operatively. The ileal segment was tapered which provides a 16 Fr. smooth tube for intermittent catheterization of the pouch. The ileocaecal junction was buttressed. Multiple 3/0 silk Lembert sutures were given to plicate the area of ileo-caecal valve, which enhances the continent mechanism. Irrigation through the caecostomy tube was done to confirm the adequacy of the continence mechanism and the completeness of the closure of reservoir. No leakage should be present when the reservoir had been filled to $300-400 \mathrm{ml}$.The reservoir is normally situated at the right lower quadrant which is the caecum orthotopic position. The stoma of ileal efferent limb was sutured flushed to the skin in the right lower quadrant. A drain tube was placed in the peritoneal cavity.

\section{Results}

Indiana pouch heterotopic continent diversion was constructed in all the 10 cases. Cystoprostatectomy was done in 5 cases of muscle invasive carcinoma urinary bladder. Pouch construction, reestablishment of bowel continuity added a mean of 4 hours (range 3-5 hours) to standard total cystoprostatectomy. There were no post-operative mortalities and the patients were followed for 6 months to 4 years (mean 1 year 6 months). Three patients lost follow-up after 12 months.

The post-operative complications are presented in Table I. In one patient there was leakage of urine in the drain tube, for which re-exploration was done, where sutures were found intact but caecostomy catheter was displaced causing leakage of urine. Wound infection was developed in 4 patients, who were managed successfully by giving proper antibiotics and regular dressing, three patients underwent additional surgical procedure of which 1 had ectopia vasicae, who developed incisional hernia one year after operation. Reconstruction with myocutaneous flap was done later on by plastic surgeons. One patient was explored for a recurrent para stomal abscess, but no fistulous tract with the efferent limb of the pouch was detected. In another case the efferent limb was kinked and 
catheterization was difficult, the patient was explored and reconstruction of the limb was done.

Table I: Post-operative complications

\begin{tabular}{lcc}
\hline & $\begin{array}{c}\text { Early (within } 30 \\
\text { days) }\end{array}$ & $\begin{array}{c}\text { Late (beyond } \\
30 \text { days) }\end{array}$ \\
\hline $\begin{array}{l}\text { Pouch related complications } \\
\text { Inability to catheterize }\end{array}$ & 1 \\
$\begin{array}{l}\text { High pressure reservoir } \\
\text { Hydronephrosis }\end{array}$ & 2 \\
$\begin{array}{l}\text { Parastomal abscess } \\
\text { Post-operative fever with } \\
\text { leakage of urine }\end{array}$ & 1 & 3 \\
$\begin{array}{l}\text { Non pouch related } \\
\text { complications } \\
\text { Wound infection }\end{array}$ & \\
$\begin{array}{l}\text { Incisional hernia } \\
\text { Post-operative ileus }\end{array}$ & & \\
Urinary tract infection & 4 & \\
\hline
\end{tabular}

Table II: Functional characteristic of Indiana pouch (simple cystometry findings)

\begin{tabular}{lrr}
\hline & $\begin{array}{c}\text { Post-operative } \\
\text { after 6 months } \\
(\mathrm{n}=7)\end{array}$ & $\begin{array}{r}12-18 \text { months } \\
(\mathrm{n}=7)\end{array}$ \\
\hline Capacity of pouch (ml) & $\begin{array}{r}380 \\
(250-650)\end{array}$ & $\begin{array}{r}530 \\
(350-700)\end{array}$ \\
$\begin{array}{l}\text { Pouch pressure at full } \\
\left.\text { capacity (cm } \mathrm{H}_{2} \mathrm{O}\right)\end{array}$ & 14 & 16 \\
$\begin{array}{l}\text { Filling volume at first } \\
\text { contraction (ml) }\end{array}$ & $(10-20)$ & $(11-22)$ \\
$\begin{array}{l}\text { Maximum reservoir } \\
\text { pressure during contraction } \\
\left.\text { (cm } \mathrm{H}_{2} \mathrm{O}\right)\end{array}$ & 180 & 290 \\
\hline $\begin{array}{l}\text { Range in parenthesis } \\
\text { (100-250) }\end{array}$ & $(150-400)$ \\
\hline
\end{tabular}

Serum survey after a mean of one year revealed mild hyper chloraemia with associated hypocarbia in 3 cases and they were treated by oral alkalinization. No patient required alternative diversion secondary to renal insufficiency or acidosis.

Post-operative IVU after first 6 months revealed some evidence of hydronephrosis without delay in function in 5 renal units. Out of 7 patients with normal upper tract, 3 lost follow-up after 6 months.

The ability to stay dry for more than 4 hours was suggested as good continence. Good continence was noted in 7 cases at day and night Mean clean intermittent self catheterization (CISC) frequency was 3.5 hours (1-5 hours range).

Simple cystometry was done in 7 patients. After 6 months the mean capacity of the pouch was $380 \mathrm{ml}$, range (250-650 ml) with an increase to $530 \mathrm{ml}$ range (350-700 $\mathrm{ml})$ at 12-18 months (Table II).

\section{Discussion}

In those patients where urethral voiding cannot be preserved after surgery continent cutaneous diversion has proved highly acceptable instead of ileal conduit with an external appliance. Given the appropriate selection of patients, the morbidity and mortality rates between standard ileal conduit and continent diversion are not significantly different ${ }^{8 \text {, }}$ 9 . As a result continent diversion provides a more attractive option for patients both socially and psychologically.

Orthotopic continent urinary diversion designed from detubularized ileum has gained widespread acceptance among urologists and the patients and is regarded as the gold standard treatment. But this needs proper patient selection.

Considering all factors in the present study 10 patients underwent Indiana pouch diversion of urine. The most time consuming part of creating the pouch involves the detubularization and reconstruction of the bowel segment. In the present study the pouch was made by manual sutures. Using a stapled technique the operation is significantly faster but several authors have noted that stapled pouches are inferior to manually sutured anastomosis in volume and pressures ${ }^{10}$. The Indiana pouch remains one of the most reliable of all catheterizable reservoirs. It is a useful urinary diversion as it is simple to construct and is associated with a low revision rate while ensuring low pressure-continence ${ }^{11}$. The patients were followed in the immediate post-operative period and at regular intervals.

In one patient there was post-operative fever with mild tenderness in the right umbilical region and leakage of urine in the drain tube for more than two weeks. We re-explored and the pouch suture lines and ureterocolonic anastomosis were found intact and leakage of urine was through the caecostomy site as the caecostomy catheter was slipped out of caecum. In a study done by Kulkarni (1992), 4 patients were reoperated for leakage of urine and they found slipped out of caecostomy catheter in 2 patients and in 2 other cases there was pericatheter leakage with intact suture in the pouch as well as ureterocolonic anastomosis. Thereafter they modified their technique and use $0.5 \mathrm{~cm}$ appendicular stump for caecostomy catheter placement, which completely eliminated the caecostomy leaks in their subsequent operation ${ }^{12}$. 
In this study three patients were hyperchloraemic and hypocarbic which may be due to irregular and delayed self catheterization and prolonged inter catheterization period and thus they were instructed for repeated catheterization. Rawland (1991) found hyperchloraemic acidosis in 7\% cases and Benson in $9 \%$ cases in their studies ${ }^{7,9}$. The status of the upper tract was evaluated 3 months after surgery and preservation of normal function was found in 7 patients, which indicates the safety of the procedure. In 3 patients there was moderate hydronephrosis and occasional fever suggesting urinary tract infection with reflux. It is believed that lowering pouch pressure by detubularization and antireflux uretero colonic anastomosis with regular self catheterization is important to limit the incidence of hydronephrosis and pyelonephritis caused by reflux. Hydronephrosis with UTI was also reported by many authors ${ }^{11-13}$.

In one left renal unit the ureter became shorter and was anastomosed with the pouch with difficulty. Horwitz and Jarrard in 2004 presented a surgical technique using the insitu appendix to provide length to a shortened ureter ${ }^{14}$. The deterioration rate of renal units in our study was 25\% (5 renal units) which was higher than ileal conduit (12-15\%) reported $^{7,9,13}$. We conceded that this is our initial experience with continent cutaneous diversion and we hope for better result subsequently.

In one patient catheterization was often difficult after few weeks due to kinking of the efferent limb (ileum), we reopened and the segment was made short. Difficulty with catheterization of the efferent limb usually is due to excessive length and tortuosity of the ileal segment. Experience by Joseph Chin and Ian Ferguson 1989 and Rowland 1987 has shown that much shorter efferent limb aimed directly at the anterior abdominal wall is sufficient for satisfactory continence as long as the application is performed securely, with special attention paid to the Lembert sutures near the ileocecal junction ${ }^{4,15}$.

Our success rate of complete continence in 7 patients (70\%) appears satisfactory and the failure in the remaining patients could be attributed to technical faults in our initial patients. Ahlering et al. (1989) reported $100 \%$ continence rate. Randall et al. (1994) reported $97 \%$ and Kulkarni $89 \%$ continence day and night ${ }^{12,13,16}$. Patients with carcinoma of the urinary bladder were given adjuvant chemotherapy. Radiotherapy is more hazardous in any diversion cases. In a comparative study more complications like ureteral stricture,obstruction,renal insufficiency and severe incontinence was found in patients who received adjuvant radiotherapy ${ }^{17}$.

In this study, 3 patients passed 5 years after operation who were advised for yearly pouchoscopy examination as stone formation and adenocarcinoma is not uncommon in Indiana pouch mostly at the anastomotic site of the ureters. Different studies showed $2-15$ years of latency period in their development ${ }^{18-20}$.

As far as pouch capacity is concerned we had good results in 7 patients (capacity 350-600 ml who are continent), which is consistent with Kulkarni $1992^{12}$.

We feel that continent urinary diversion is more acceptable to patients, though patient has to accept a stoma over the abdominal wall which is flushed to the skin and can be covered with a gauze. However it requires intermittent self catheterization for evacuation of urine.

In conclusion, this study suggests that the Indiana pouch provides a better alternative for urinary diversion with good continence and satisfactory renal function.

\section{Authors' contribution}

SMMA: Main surgeon of the operating team, data collection and manuscript writing

MMH: Assists in operation, data collection and manuscript writing

MH: Assists in operation, data collection and manuscript writing

MR: Assists in operation, data collection and manuscript writing

\section{Reference}

1. Pitts WR Jr, Muecke EC. A 20 years experience with ileal conduits: The fate of the kidneys. J Urol. 1979; 122: 154-57.

2. Kock NG, Nilson LO, Norten LJ, Philipson BN. Urinary diversion via continent ileal reservoir: Clinical results in 12 patients. J Urol. 1982; 128: 469-75.

3. Skinner DG, Lieskovsky G, Boyd SD. Technique of creation of a continent internal ileal reservoir (Kock pouch) for urinary diversion. Urol Clin North Am. 1984; 11: 741-49.

4. Rowland RG, Mitchell ME, Bihrle R. The cecoileal continent urinary reservoir. J Urol. 1987; 137: 1136-39.

5. Gilchrist RK, Merricks JW, Hamlin HH. Construction of a substitute bladder and urethra. Surg Gynaecol Obstet. 1950; 90: 752-60.

6. Gallucci M, Leonardo C, Guaglianone S, Roccheggiani A, Aicini A, Flammia GP, Forestiere E. Simplified 
Indiana pouch with multiple teniamyotomics. Urology 2006; 67: 93-96.

7. Holmes DG, Thrasher JB, Park GY, Kueker DC, Weigel JW. Long-term complications related to the modified Indiana pouch. Urology 2002; 60: 603-06.

8. Wood DP Jr. Methods of urinary diversion following radical cystectomy. J Kentucky Med Assoc. 1994; 92: 96-100.

9. Benson MC, Slawin KM, Wechsler MH, Olsson CA. Analysis of continent versus standard urinary diversion. Brit J Urol. 1992; 69: 156-62.

10. Montie JE, Pontes JE. Powell IJ. Comparison of the Wstapled ileal reservoir with hand sewn reservoirs for orthotopic bladder replacement. Urology 1996; 46: 476-81.

11. Salome F, Paulhac P, Hodonou R, Colombeau P, Pfeifer P. The Indiana pouch: A technique for simple continent urinary diversion. J Prog Urol. 1997; 7: 41521.

12. Kulkarni HB, Tongaonkar R, Kamat MR. Continent urinary reservoir. Brit J Urol. 1992; 69: 513-17.

13. Ahlering TD, Weingberg AC, Razor B. A comparative study of ileal conduit, Kock pouch and modified Indiana pouch. J Urol. 1989; 142: 1193-96.
14. Horwitz GJ, Jarrard DF. Extension of a shortened ureter using the insitu appendix during Indiana pouch urinary diversion. Urology 2004; 63: 167-69.

15. Chin JL, Ferguson IK. Intermittent difficulty with catheterization of Indiana continent urinary reservoir: Use of flexible ureteroscope. J Urol. 1989; 142: 371.

16. Sullivan LD, Chow VDW, Ko DSC, WrightJE, McLoughlin MG. An evaluation of quality of life in patients with continent urinary diversions after cystectomy. Brit J Urol 1998; 81: 699-704.

17. L'esperance JO, Lakshmann Y, Trainer AF, Jiang Z, Blute RD Jr, Ayvazian PA. Adenocarcinoma in an Indiana pouch after cystectomy for transitional cell carcinoma. J Urol. 2001; 165: 901-02.

18. Gazzaniga MS, Turbow B, Ahlering TE, Shanberg AM. Adenocarcinoma in an Indiana pouch urinary diversion. J Urol. 2000; 163: 900.

19. Komai Y, Kawakita M, Shimada O, Muguruma K. Colonic adenocarcinoma and stones in an Indiana pouch. Int J Urol. 2005; 12; 412-13.

20. Saito R, Mishima H, Nishikawa N, Ueda T, Kim CJ. Colonic adenocarcinoma in an Indiana pouch successfully treated by endoscopic mucosal resection. Int J Urol. 2007; 14: 661-62. 